\title{
Chemotherapy-induced anemia: etiology, pathophysiology, and implications for contemporary practice
}

This article was published in the following Dove Press journal: International Journal of Clinical Transfusion Medicine

\section{Emily Bryer \\ David Henry}

Internal Medicine, Pennsylvania Hospital, University of Pennsylvania

Health System, Philadelphia, PA, USA
Correspondence: Emily Bryer

Pennsylvania Hospital, 800 Spruce Street, Philadelphia, PA 19107, USA

Tel + I 26758 I 4I66

Email Emily.Bryer@uphs.upenn.edu

\begin{abstract}
Chemotherapy-induced anemia (CIA) is a multifaceted entity influenced by a variety of patient- and treatment-specific factors. Some sources of variation within CIA include chemotherapeutic agent as well as dose and administration schedule, type and stage of malignancy, baseline pretreatment hemoglobin, target hemoglobin, timing of intervention (red blood cell transfusion, iron, erythropoietin stimulating agent), nutritional status, renal function, age, and gender. The diversity of patient presentation and symptomatology within the broader spectrum of CIA contributes to the challenge of establishing universal criteria to govern optimal management therapies. This manuscript will review the development and evolution of CIA with an emphasis on assorted therapeutic interventions.
\end{abstract}

Keywords: chemotherapy-induced anemia, red blood cell transfusion, erythrocyte stimulating agent, iron

\section{Introduction}

Anemia, derived from the Greek word "anaimia" meaning lack of blood, refers to a decreased oxygen-carrying capacity in the blood and is commonly associated with cancer. ${ }^{1}$ Anemia is the most common and persistent hematological abnormality in oncology patients. ${ }^{2}$ Chemotherapy-induced anemia (CIA) is a consequence of malignant invasion of normal tissue leading to blood loss, bone marrow infiltration with disruption of erythropoiesis, and functional iron deficiency as a consequence of inflammation. ${ }^{3}$ CIA is a significant consequence of chemotherapy and may delay or limit therapy as well as contribute to both fatigue and diminished quality of life. ${ }^{4}$ Unfortunately, not all clinicians consistently survey, measure, or even document anemia-related symptoms. Furthermore, there are inconsistent thresholds for both the definition and the severity of anemia. The lack of standardized objective grading systems of anemia and its varying manifestations make its quantitative evaluation challenging. Although some literature defines anemia by a reduction from baseline hemoglobin, the use of blood transfusions, or the use of recombinant human erythropoietin therapy, ${ }^{5}$ others fail to document the toxicity grading system used to define anemia. ${ }^{6}$ The National Cancer Institute Anemia Scale proposed the following grading scale for anemia ${ }^{7}$ :

- Grade $0=$ Normal limits $=$ hemoglobin $12-16 \mathrm{~g} / \mathrm{dL}$ for women and $14-18 \mathrm{~g} / \mathrm{dL}$ for men

- Grade 1 = Mild = 10-12 g/dL for women and 10-14 g/dL for men

- Grade $2=$ Moderate $=8-10 \mathrm{~g} / \mathrm{dL}$ 
- Grade $3=$ Severe $=6.5-8 \mathrm{~g} / \mathrm{dL}$

- Grade $4=$ Life threatening $=<6.5 \mathrm{~g} / \mathrm{dL}$

- Grade $5=$ Death

Partially a consequence of the heterogeneity of CIA, there are large disparities among its reported prevalence. Patients receiving chemotherapy often have comorbid conditions including inadequate renal function, a baseline factor that has not been consistently excluded in prior analyses of CIA. Despite the variability in definitions, as well as the difficulty of objectivity of measurement due to confounding variables, an estimated $70 \%$ of patients receiving chemotherapy develop anemia. ${ }^{8,9}$ Hematologic supportive care strategies such as bone marrow transplant or peripheral blood stem cell support are essential to mitigate the cytotoxic effects of high-dose chemotherapy.$^{10}$ While transfusion rates vary in patients with CIA, about $50 \%$ of patients with incurable cancer require at least one red blood cell transfusion prior to completing chemotherapy treatment. ${ }^{11}$

High-dose chemotherapy capitalizes on a theoretical dose-response relationship with the notion that higher doses are correlated with higher response rates. ${ }^{10}$ Unfortunately, chemotherapy affects all rapidly dividing cells, including the particularly sensitive erythroid progenitor cells in a process known as eryptosis. ${ }^{12}$ Analogous to apoptosis of nucleated cells, erythrocytes undergo eryptosis to destroy and remove defective erythrocytes, thereby preventing hemolysis and subsequent hemoglobin release. ${ }^{13}$ Eryptosis and resultant erythrocyte deficiency contributes to anemia and is exacerbated by inadequate compensatory erythropoiesis. ${ }^{13,14}$ In advanced hematologic malignancies, cytokine release from tumor cells is a main mechanism by which erythropoiesis is disrupted. These cytokines, including interferon-gamma, IL-1, and tumor necrosis factor, disrupt endogenous erythropoietin synthesis in the kidney and suppress differentiation of erythroid progenitor cells in the bone marrow. ${ }^{15}$

CIA is most frequently observed in hematologic, particularly myeloid, malignancies more so than in solid tumors. ${ }^{16}$ Of all cancers, lymphomas, lung tumors, gynecologic, and genitourinary tumors have the highest incidence of anemia with at least $50 \%-60 \%$ requiring transfusion. ${ }^{17}$ Among solid tumors, patients with lung cancer require the highest frequency of transfusion and are typically transfused at higher hemoglobin levels which has been attributed to both older age and suspicion of concurrent pulmonary disease. ${ }^{11,18}$ Anemia at baseline prior to initiation of chemotherapy is associated with an increased incidence of CIA and patients with prechemotherapy hemoglobin levels $<11 \mathrm{~g} / \mathrm{dL}$ are more likely to receive a red blood cell transfusion than those with normal baseline hemoglobin levels. ${ }^{8}{ }^{818}$ A variety of characteristics are predictive of CIA and corresponding blood transfusion requirements, some of which include response to iron treatment, ${ }^{3}$ advanced age, ${ }^{17}$ presence of metastases, ${ }^{19}$ the degree of hemoglobin decrease within the first month of treatment, as well as tumor type and treatment duration. ${ }^{16}$ Furthermore, patients with advanced cancers are typically more anemic at diagnosis and have worse survival outcomes. ${ }^{15}$ The degree of CIA is directly proportional to the number of repeated chemotherapy cycles despite transfusion, inferring limitations regarding the duration of transfusion benefit. ${ }^{19}$

CIA is often precipitated by platinum-based therapies. ${ }^{20}$ Factors that are associated with the development of platinuminduced anemia include early decrease in hemoglobin following treatment, cumulative platinum dose, advanced age, failure to respond to chemotherapy, and high concentration of residual platinum in the bloodstream following administration. ${ }^{16,21}$ Mechanisms of CIA by platinum-based regimens involve direct suppression of erythroid progenitor cells within the bone marrow as well as nephrotoxic effects on erythropoietin-producing cells within the kidney. ${ }^{22,23}$ States of inherent erythropoietin deficiency secondary to cisplatininduced renal tubular damage can be prevented or treated by replacement with recombinant hormone. ${ }^{24}$ Nonplatinumbased chemotherapy regimens, including antimicrotubular agents, campothecins, and biologics, can also be particularly myelosuppressive..$^{25,26}$

Fatigue is the most common symptom of CIA, although vertigo, loss of appetite, poor concentration, and dyspnea are also frequently reported. ${ }^{27}$ Grade of anemia in combination with type of cancer and baseline cardiopulmonary function contribute to symptom severity. ${ }^{28}$ Although the relationship between anemia and fatigue is difficult to quantify, fatigue has the most significant adverse effect on quality of life. ${ }^{6}$ The acuity of anemia affects corresponding symptomatology with acute-onset anemia resulting in more prominent symptoms. As expected, anemia that develops progressively allows for adaptive mechanisms to adjust for decreased oxygen-carrying capacity and therefore does not usually present with acute symptoms. Some of these adaptive mechanisms include increases in coronary blood flow and cardiac output as well as altered blood viscosity and changes in oxygen utilization. ${ }^{7}$

\section{Implications of CIA and suboptimal response to current chemotherapy in anemic patients}

The two primary objectives of CIA treatment are to alleviate symptoms and to improve quality of life. ${ }^{29}$ Failing to treat CIA 
may contribute to a suboptimal response to chemotherapy and correction of anemia in patients is correlated with improved responses to chemotherapy. ${ }^{2,30}$ Apoptotic failure and cell cycle quiescence are two potential mechanisms of chemotherapy resistance in anemic patients. ${ }^{31}$ Furthermore, inadequate bone marrow recovery following cytotoxic therapy as manifested by anemia, thrombocytopenia, and neutropenia is responsible for most chemotherapy dose delays and dose reductions. ${ }^{32-34}$ In patients with both solid and liquid malignancies, the development of severe anemia during the first cycle of chemotherapy is associated with an increased risk of dose delay and/or dose reduction in the subsequent chemotherapy cycle, regardless of age, gender, race/ethnicity, cancer stage, chemotherapy cycle, absolute neutrophil count, platelet counts, liver function, renal function, and history of other comorbidities. ${ }^{34}$ These data suggest that the development of moderate to severe anemia directly affects subsequent chemotherapy administration and prevention and that timely management may result in fewer dose reductions and delays. ${ }^{34}$ In the setting of chemotherapyinduced myelosuppression, many oncologists reduce doses by $20 \%$ in hopes to limit excess cytotoxic effects on the bone marrow; unfortunately, a $20 \%$ dose reduction may lead to a $50 \%$ reduction in cure rate. ${ }^{10}$

Low hemoglobin is associated with both adverse outcomes and reduced tumor oxygenation. ${ }^{35-37}$ Decreased oxygen-carrying capacity with resultant tumor hypoxia may be associated with increased mortality. ${ }^{38}$ Rapid proliferation and division of solid tumor cells can obstruct and compress blood cells, leading to tissue hypoxia. ${ }^{39}$ Some clinicians interpret the correlation between anemia and poor tumor oxygenation as a rationale for treatment with red blood cell transfusions. ${ }^{37}$ Some hypotheses regarding decreased survival in patients with CIA include reduced tumor-free radical formation with corresponding upregulation of hypoxia-inducible genes, including $H I F-1$ to augment cellular function. ${ }^{39,40}$ Activation of $H I F-1$ triggers the transcription of over 100 downstream genes that orchestrate cellular function and are necessary for tumor viability. ${ }^{39}$ Consequently, hypoxia modifies cancer cell metabolism to induce cell quiescence and minimize cell division, thereby limiting the effects of cytotoxic chemotherapeutic agents. ${ }^{41}$ This can be problematic, especially because many chemotherapy regimens require oxygen for cytotoxic function. Additionally, hypoxia induces tumor growth via enhancement of neoangiogenesis, genetic mutations, and free radical formation. ${ }^{42,43}$

\section{Current therapeutic strategies for CIA}

Current practices to treat CIA include packed red blood cell transfusions, erythropoietin stimulating agents (ESAs), and iron supplementation. ${ }^{44}$ The goal of red blood cell transfusion is to maintain or improve the oxygen-carrying capacity in the blood to facilitate oxygen delivery to tissues. ${ }^{7}$ Red blood cell transfusions are indicated in patients with cancer who are hypovolemic and refractory to fluid resuscitation with crystalloid infusions, patients with cancer and chronic symptomatic anemia unresponsive to iron supplementation, and patients with cancer who require rapid correction of hemoglobin. ${ }^{45}$ Despite the aforementioned indications for transfusion in patients with malignancy, there are currently no randomized controlled trials that evaluate the use of red blood cell transfusions or the use of red blood cell transfusions with ESA in patients with cancer. ${ }^{29}$ Although it is known that hemoglobin significantly influences survival in patients receiving chemotherapy, it remains controversial whether or not improving hemoglobin by blood transfusion improves treatment response. ${ }^{46}$

The major benefit of treating symptomatic anemia with homologous blood transfusion is the speed of resolution of anemia symptoms with each unit correlated with a hemoglobin rise of $1 \mathrm{~g} / \mathrm{dL} .{ }^{15}$ Preparation of packed red blood cells prior to transfusion involves removing plasma from whole blood with centrifugation of the sediment and erythrocytes. Despite most platelets being removed from whole blood to prepare packed red blood cells, the remaining platelets as well as leukocytes are responsible for immunomodulatory effects in the recipient. ${ }^{14}$ Red blood cells, also known as erythrocytes, originate from pleuripotent stem cells and are stimulated by iron and chemical growth factors to proliferate. ${ }^{47}$ An erythrocyte has a lifespan of 90-120 days in human serum and, as a result, detection of treatment-associated anemia may not manifest for 4-6 weeks following receipt of myelosuppressive therapy. ${ }^{47}$

An estimated $15 \%$ of the blood resources in the USA are allocated to hematology/oncology patients. ${ }^{48}$ In contemporary practice, clinicians determine whether or not to transfuse a patient, when to transfuse, as well as the quantity of units to transfuse. Remarkably, variation among clinician's decision to transfuse patients is as subjective as the corresponding patient's symptomatology. Analysis of transfusion patterns in patients with CIA reveal that fatigue is the most common driving factor of transfusion, followed by hemoglobin level. It is difficult to discern whether or not a patient's symptoms prompting a transfusion are due to his or her primary malignancy, a consequence of the treatment on physiologic function or respiratory mechanics, or a reflection of anemia itself. For example, breathlessness is most frequently reported in patients with lung cancer compared to other malignancies, which may contribute to a lower transfusion threshold. ${ }^{19}$ 
On average, $15 \%$ of anemic cancer patients receive red blood cell transfusions and, when transfused, usually receive two units. ${ }^{49}$ Liberal red blood cell transfusions are of limited benefit - they are not well supported by evidence and increase the risk of adverse events..$^{50}$ Among patients with CIA, a single-unit transfusion policy is associated with a $25 \%$ reduction of red blood cell usage per therapy cycle in comparison to a double-unit transfusion policy. ${ }^{51}$ The lack of increased adverse events with a restrictive threshold in conjunction with the known risks of blood transfusion support the transfusion of the minimal number of units necessary titrated to symptom improvement.

\section{Current red blood cell transfusion guidelines}

The American Association of Blood Banks and the European Society of Medical Oncology both issue guidelines for red blood cell transfusion (Table 1). Among patients receiving chemotherapy, the "National Comprehensive Cancer Network (NCCN)" 2018 guidelines (Table 1) recommend evaluation and correction of coagulopathies as well as evaluation of folate, B12, and iron deficiencies prior to initiating myelosuppressive chemotherapy. NCCN guidelines for use of red blood cell transfusions in patients with CIA do not support the use of a "trigger threshold" or specific value to determine transfusion necessity. ${ }^{7}$

Optimal transfusion strategies should include assessment of other factors in addition to grade of anemia or level of hemoglobin - at times, transfusions are indicated with hemoglobin concentrations between 7 and $10 \mathrm{~g} / \mathrm{dL}$ when patients have significant underlying comorbidities including cardiopulmonary disease, bone marrow failure, or other hematological diseases. ${ }^{53-55}$ Notably, transfusion of red blood cells to hemoglobin above $7 \mathrm{~g} / \mathrm{dL}$ does not translate to increased oxygen delivery. ${ }^{1}$

\section{Historical controversy surrounding red blood cell transfusion}

Although red blood cell transfusion has the potential to rapidly improve hemoglobin, adverse events occur following $1 \%-3 \%$ of transfusions. ${ }^{56}$ Some of these adverse events include thrombosis, infections, immunologic compromise, transfusion-related acute lung injury, nonimmunogenic hemolytic reactions, hemolysis of incompatible red blood cells or incompatible plasma, allergic reaction, and formation of human leukocyte antigen antibodies. ${ }^{29,57}$ Hemodynamic and hematologic consequences associated with expanded red blood cell mass include hypertension, transfusion-associated circulatory overload, and decreased renal and cerebral blood flow. ${ }^{22,58}$ As patients require more numerous and more frequent blood transfusions, the risks of transfusion dependence, transfusion-transmitted infection, allergic response, and severe transfusion reactions increase. ${ }^{55}$ In addition to the aforementioned risks, red blood cell transfusions may interact deleteriously with chemotherapy. ${ }^{45}$

Blood can be stored for up to 42 days following donation, although its quality progressively declines as storage time increases. Longer storage of blood is associated with changes in red blood cell metabolism, shape, and rheology; loss of membrane carbohydrates, lipids, and proteins; as well as alterations in secretion, adhesion, and oxygen delivery. ${ }^{58,59}$ In vitro models of pancreatic adenocarcinoma showed progression and migration of malignancy that correlated with longer length of packed red blood cell storage time prior to transfusion. ${ }^{60}$ The most frequent complication of blood transfusion is delayed hemolytic reaction followed by transfusion-associated acute lung injury.22 However, the majority of immunologic and infectious problems due to blood transfusions are a consequence of donor leukocytes within the transfusion. Viruses transmitted by blood transfusion utilize leukocytes as the vector to infect the host, the

Table I Indications/recommendations for red blood cell transfusion

\begin{tabular}{|c|c|}
\hline Organization & Guideline \\
\hline $\begin{array}{l}\text { American Association of Blood Banks } \\
(A A B B)^{52} \\
(2016)\end{array}$ & $\begin{array}{l}\text { - Maintain hemoglobin } \geq 7 \mathrm{~g} / \mathrm{dL} \text { in hemodynamically stable hospitalized patients } \\
\text { - Consider transfusion in patients with hemoglobin } \leq 8 \mathrm{~g} / \mathrm{dL} \text { and preexisting cardiovascular disease } \\
\text { - Personalize all transfusions by both symptoms and hemoglobin levels }\end{array}$ \\
\hline $\begin{array}{l}\text { European Society of Medical Oncology } \\
(\text { ESMO })^{29} \\
(2018)\end{array}$ & $\begin{array}{l}\text { - Recommend transfusion in patients with hemoglobin level }<7-8 \mathrm{~g} / \mathrm{dL} \text { and/or with severe anemia- } \\
\text { related symptoms, regardless of hemoglobin level }\end{array}$ \\
\hline $\begin{array}{l}\text { National Comprehensive Cancer } \\
\text { Network }(\mathrm{NCCN})^{7}(2018)\end{array}$ & $\begin{array}{l}\text { - Recommend transfusion of patients with symptomatic anemia } \\
\text { - Monitor and reevaluate patients with asymptomatic anemia who lack significant comorbidities } \\
\text { - Consider transfusion in patients who are at high risk with progressive hemoglobin decline in the } \\
\text { setting of recent chemoradiation or asymptomatic with comorbidities such as cardiopulmonary or } \\
\text { cerebrovascular disease }\end{array}$ \\
\hline
\end{tabular}


most common of which is hepatitis $\mathrm{B} .^{22}$ Other viruses that are less likely to be transmitted include hepatitis C, HIV, hepatitis A virus, cytomegalovirus (CMV), Epstein-Barr virus, human-herpes-virus 8, toxoplasma, parvovirus B-19, West Nile virus, spongiform encephalopathy prions, Chagas, Babesia, and malaria. ${ }^{22}$

Antigen exposure via donor blood impacts the immune function of the recipient and may result in alloimmunization and downregulation of immune responses (also known as transfusion-associated immunomodulation or TRIM). ${ }^{61}$ TRIM may be associated with enhancement of neoplastic proliferation. ${ }^{62}$ As a result, some clinicians choose to transfuse leukoreduced blood, which is filtered to decrease the quantity of leukocytes below 5.106 leukocytes/component. ${ }^{52}$ The administration of leukoreduced red blood cells has resulted in a lower incidence of TRIM, fewer febrile nonhemolytic transfusion reactions, a lower incidence of HLA sensitization in recipients, and a lower probability of CMV transmission. ${ }^{55}$ Ideally, leukoreduction of blood occurs early in the storage period to diminish and hopefully prevent cytokine production. ${ }^{57}$ The administration of leukoreduced blood does not, however, completely eliminate the transmission of pathogens and cytokines due to the tendency of leukocytes to adhere to plastic in storage - preventing removal with leukoreduction. ${ }^{22}$ While currently there is a current lack of evidence that patients with cancer who receive leukoreduced blood have improved outcomes, given the known risks of leukocyteattributed transfusion reactions, leukoreduced blood may be beneficial in patients in whom multiple blood transfusions are anticipated. ${ }^{1}$

Malignancy and toxicity-induced inflammatory cytokine cascades reduce erythropoietic function and affect iron homeostasis. ${ }^{29}$ Blood transfusions increase prostaglandin $\mathrm{E}$ as well as both local and circulating proinflammatory cytokines, some of which include angiogenin, tumor necrosis factor-alpha, EGF, and platelet-derived growth factor BB. ${ }^{60}$ Notably, these cytokines remain in blood despite leukoreduction and their concentration increases with storage time. ${ }^{60,63}$ Due to recognized immunomodulatory effects, red blood cell transfusions may influence neoplastic development and proliferation. ${ }^{64}$ Patients with colorectal, head and neck, breast, gastric, and prostate cancer who received blood transfusions have significant increases in mortality, recurrence, and death from cancer recurrence. ${ }^{62}$ Increased rates of malignancy following blood transfusion may be secondary to transfusionrelated immunomodulatory effects that revealed undiagnosed occult malignancies. ${ }^{65}$ Whether or not high mortality and recurrence in patients with malignancy who receive blood transfusions is a reflection of the tumor-specific aggression that drove the need for transfusion, a function of the blood transfusion itself, or a consequence of the recipients' reaction to the transfusion remains unclear.

In addition to various immunomodulatory effects, red blood cell transfusions are associated with venous and arterial thromboses as well as in-hospital mortality. ${ }^{66}$ Approximately $20 \%$ of patients with cancer experience a venous thromboembolism (VTE) during their therapy course. ${ }^{67}$ Some factors that may contribute to the development of VTE in patients with cancer include history of a VTE, inherited or acquired mutations, hypercoagulability, cell surface expression of tumor factor, cytokine-mediated activation of coagulation cascade, baseline thrombocytosis, recent immobilization/ surgery, hormonal agents, steroids, and hypertension. ${ }^{7}$ While immunomodulatory effects and thromboses are associated with red blood cell transfusion, iron overload is typically a less likely consequence and does not typically occur in patients who receive transfusions limited to the time of their chemotherapy treatment. ${ }^{7}$

\section{Erythropoiesis stimulating agents in CIA}

Erythropoietin (EPO) was initially identified in 1906 and is a circulatory hematopoietic glycoprotein hormone that facilitates erythrocyte production. ${ }^{68}$ EPO is expressed by renal and hepatic interstitial cells and is upregulated in the setting of hypoxia to stimulate erythrocyte production in the bone marrow. ${ }^{68,69}$ Following secretion by the liver and kidneys, EPO binds to erythroid precursor cells to induce both maturation and differentiation. ${ }^{68}$ ESAs are a class of recombinant medications that induce red cell proliferation via utilization of iron stores that are necessary for effective erythropoiesis. ${ }^{67}$ ESAs are categorized by their duration of action and are divided into short-acting (epoetin alfa, epoetin zeta, epoetin beta, and epoetin theta) and long-acting (darbepoetin alfa) ESAs. ${ }^{70}$

In the early 1980s, anemia was an expected consequence of both cancer and chemotherapy and the treatment was red blood cell transfusion. Historically, the transfusion threshold was around $8 \mathrm{~g} / \mathrm{dL}$ and, occasionally, physicians transfused patients according to symptoms. Toward the late 1980s, Amgen cloned epoetin alfa soon to be followed by darbepoetin alpha (molecule with extra sugar moieties), and these drugs were approved for CIA in the early 1990s. Both epoetin alfa and darbepoetin alpha have been showed to increase quality of life when compared to placebo. ${ }^{71,72}$ Several disease states including endstage renal disease, HIV, and CIA have 
demonstrated an association between higher hemoglobin levels and improved quality of life. ${ }^{73-77}$

In the late 1990s, those studying CIA and ESA gave higher doses of ESA to drive hemoglobin up even more until safety signals were issued, one of which was in the "BEST" trial in breast cancer patients with CIA on epoetin alfa. ${ }^{78}$ In response to these safety signals, the US Food and Drug Administration (FDA) held an Oncology Drug Advisory Committee that reviewed the data regarding ESA use at higher hemoglobin levels and selected a finite threshold of 10 $\mathrm{g} / \mathrm{dL}$ for administration of ESA despite the quality of life data being above the 2006 FDA black box warning that ESAs in CIA can hasten tumor growth and/or shorten survival; ${ }^{79}$ this was independently reviewed by the Cochrane meta-analysis people and some 60 trials via meta-analysis did not show this tumor growth or any negative survival. ${ }^{80}$ Nevertheless, the FDA required Procrit and Aranesp to undergo breast cancer and lung cancer anemia (CIA) trials, respectively, ESA vs placebo. After nearly 10 years and testing thousands of patients, both studies have reported no difference in survival putting this issue to rest. ${ }^{81,82}$ Unfortunately, oncology treaters are still frightened by the FDA ruling, and ESA use in CIA took and continues to take a significant downturn. Simultaneously with the decreased use of ESAs in CIA, the transfusion requirement increased; however, this has been partially offset by decrease in transfusion threshold to 7.5 $\mathrm{g} / \mathrm{dL}$ or even $7 \mathrm{~g} / \mathrm{dL}$.

ESAs are used in many types of anemia and have a prominent role in CIA. ESA administration in patients with CIA results in an improvement of hemoglobin by $40 \%-70 \%{ }^{83}$ Patients with rare blood groups, religious beliefs restricting blood transfusions, and/or risks of cerebral or myocardial ischemia are at higher risk for the development of CIA and may benefit from preventive administration of ESA ${ }^{84}$ Although there has been some historical uncertainty regarding their safety profile, a meta-analysis of 60 studies demonstrated that ESA utilization had no significant impact on disease progression. ${ }^{80}$ Administration of ESA in CIA is associated with fewer red blood cell transfusions, improved quality of life, as well as improved mood and cognitive function in cancer patients receiving chemotherapy. ${ }^{1,26}$ ESA is indicated following correction of iron deficiency and other causes of anemia in patients with CIA who are symptomatic with a hemoglobin level $<10 \mathrm{~g} / \mathrm{dL}$ or for patients who are asymptomatic with a hemoglobin level $<8 \mathrm{~g} / \mathrm{dL} .{ }^{29}$ Prescribing restrictions regarding the initiation of ESA in patients with hemoglobin $<10 \mathrm{~g} / \mathrm{dL}$ and discontinuing therapy for patients with hemoglobin $>10 \mathrm{~g} / \mathrm{dL}$ has translated into diminished severity and duration of CIA with less use of ESA and fewer blood transfusions..$^{85,86}$

ESAs are remarkably safe except for their increased risk of thrombosis that is often underappreciated by clinicians. Treatment of CIA with ESA increases the risk of VTE by $50 \%$ and may be influenced by iron-restricted erythropoiesis. ${ }^{67}$ Data from five meta-analyses demonstrated a 48\%-69\% increase in the relative risk of thrombotic events in patients receiving chemotherapy coupled with ESA. ${ }^{7,80,87-90}$ Mechanisms of ESA-induced thromboembolic disease may include elevated blood viscosity as a consequence of increased red blood cell mass in the setting of plasma volume contraction, nitric oxide scavenging, and endothelial cell activation. ${ }^{22}$ There have been no prospective randomized trials to date with evidence to support anti-thrombotic therapy as a recommended strategy to decrease venous thromboembolisms in patients with malignancy receiving ESA. ${ }^{29}$

\section{Evidence and indications for iron supplementation in CIA}

Erythrocyte production is limited by iron availability with a $20 \mathrm{mg}$ daily requirement - the majority of which is obtained from degraded hemoglobin. ${ }^{91}$ Iron availability is reduced by an estimated $44 \%$ in the setting of inflammation. ${ }^{92}$ Despite adequate iron stores, functional iron deficiency in the setting of inflammation leads to iron sequestration in macrophages and enterocytes, preventing bone marrow utilization for erythrocyte production, leading to anemia. ${ }^{93}$ Prior to initiation of an ESA, iron studies are necessary to exclude baseline iron deficiency, since stimulating erythropoiesis requires bioavailable iron for an optimal response..$^{3,83,94-96}$ Iron deficiency anemia in malignancy develops as a consequence of tumor-site blood loss, suppressed erythropoiesis from neoplastic bone marrow infiltration, as well as cytokine-induced suppression of iron utilization..$^{97}$ Despite normal or high ferritin levels, decreased transferrin saturation in cancer patients indicates functional iron deficiency that may be due to either iron sequestration or increased iron requirements in the setting of ESA therapy. ${ }^{92,93,98,99}$

Hepcidin, an acute phase reactant produced in the setting of inflammation, is the main iron regulator and frequently impairs iron homeostasis in cancer patients. ${ }^{92}$ Hepcidin is renally metabolized, so patients with renal insufficiency may have even more elevated levels of hepcidin with resultant reduced oral iron absorption. ${ }^{100}$ Iron supplementation is an underutilized therapy of CIA that has historically relied on the oral form. ${ }^{44}$ Unlike the oral form that is limited by hepcidin, intravenous iron is directly engulfed by macrophages and is 
not limited by a disrupted absorption system in the inflammatory setting..$^{93,100}$ Intravenous iron is indicated in CIA in patients with a hemoglobin level $\leq 11$ or who have a decrease in hemoglobin level $\geq 2 \mathrm{~g} / \mathrm{dL}$ from a baseline level of $\geq 12$ $\mathrm{g} / \mathrm{dL}$ in the setting of absolute iron deficiency as defined by serum ferritin $<100 \mathrm{ng} / \mathrm{mL}^{29}$

Bone marrow response to ESAs in patients with CIA is variable and ranges from $35 \%$ to $70 \%$, limited by iron deficiency, tumor proliferation, infections, and baseline bone marrow functionality. ${ }^{93,98,101}$ Patients with appropriate baseline iron stores may respond adequately to inherent EPO production; however, administration of external ESAs requires additional iron supplementation to satisfy the increased requirements of erythropoiesis. ${ }^{100,102}$ Since iron supply to the bone marrow is the rate-limiting step in the development, proliferation, and maturation of erythrocytes, iron supplementation may be necessary in functional iron deficiency to optimize response to patients with CIA receiving ESA. ${ }^{96}$ Among patients with CIA receiving epoetin alfa, oral iron supplementation is inadequate to prevent iron-restricted erythropoiesis. ${ }^{96}$ Although intravenous iron therapy alone reduces requirements for red blood cell transfusions, it has a synergistic effect when used with ESA with a 50\%-70\% improved response rate and correction of anemia with fewer required transfusions and improved quality of life. ${ }^{100,103,104}$ Furthermore, the absence of intravenous iron-induced clinically significant toxicity in patients receiving ESA supports its role in the CIA treatment paradigm. ${ }^{105}$ While intravenous iron significantly augments ESA function, there is an absence of long-term data regarding its use. ${ }^{29}$

\section{Recommendations for optimum prevention and management of CIA}

The heterogeneity among patients with malignancies, coupled with the diverse pathophysiology of anemia in cancer, necessitates the personalization of guidelines for the treatment of CIA. ${ }^{103}$ Ideally, anemia is quantified and recorded throughout the chemotherapy cycle with a universal scale that is consistent across health care institutions; one such example includes the scale provided by the NCCN and mentioned at the beginning of this paper. ${ }^{7}$ CIA is associated with poor survival and has significant effects on patient quality of life and chemotherapy response. While it is not consistently and objectively surveyed, symptoms of anemia are important to quantitate with the awareness that symptomatology is, in part, dependent on the acuity of anemia development. There is evidence to support a positive correlation between higher hemoglobin levels and improved quality of life, a critical point to consider when weighing the risks and benefits of either red blood cell transfusion and/or ESA administration. The following bulleted summary and Table 2 encompass recommendations presented in this manuscript and represent a reasonable approach to the prevention and management of CIA.

\section{Prior to myelosuppressive chemotherapy}

- Patients should be evaluated for risk of CIA development with measurement of reticulocyte count, iron stores, vitamin B12 and folate with appropriate repletion and correction prior to initiation of cytotoxic therapy.

\section{Red blood cell transfusion}

- Although there is no universal hemoglobin threshold to govern red blood cell transfusion, it may be considered when hemoglobin levels decrease below $8 \mathrm{~g} / \mathrm{dL}$. Therefore, red blood cell transfusion in patients with CIA should be limited to patients with 1) symptomatic anemia and/or 2) significant comorbidities and titrated to resolution of symptoms by administering one unit of blood at a time. When possible, the use of leukoreduced and CMV-negative blood may help reduce morbidities associated with transfusions.

\section{EPO stimulating agents}

- In patients with symptomatic CIA with a hemoglobin level $\leq 10 \mathrm{~g} / \mathrm{dL}$, ESA may be considered following exclusion of hemoglobinopathies. ${ }^{29}$ If indicated, intravenous iron and/or ESA use guided by current recommendations may be used to treat CIA and thereby reduce the need for red blood cell transfusion.

- ESA should not be offered to most patients with nonchemotherapy-induced anemia.

- Optimistically, long-term data regarding ESA use in malignancy and the monitoring of serum ferritin as a determinate of response to ESA therapy may guide in administration, thereby maximizing therapeutic benefit with minimization of adverse treatment effects.

\section{Iron supplementation}

- In addition to its role as an adjunctive therapy with ESA in CIA as discussed earlier, intravenous iron alone reduces blood transfusion requirements in patients with CIA. Iron supplementation, in the intravenous form specifically, is recommended in patients with CIA with a hemoglobin level $\leq 11 \mathrm{~g} / \mathrm{dL}$ or a decrease in hemoglobin by $\geq 2 \mathrm{~g} / \mathrm{dL}$ from a baseline level of $\geq 12 \mathrm{~g} / \mathrm{dL}$ in the setting of absolute iron deficiency as defined by serum ferritin $<100 \mathrm{ng} / \mathrm{mL}^{29}$ 
Table 2 Therapeutic interventions in CIA

\begin{tabular}{|c|c|c|c|}
\hline Therapy & Indications & Advantages & Disadvantages/side effects \\
\hline RBC transfusion & $\begin{array}{l}\text { - Symptomatic } \mathrm{ClA} \\
\text { - Consider when } \mathrm{Hb}<8 \mathrm{~g} / \mathrm{dL} \\
\text { - Consider comorbidities } \\
\text { - Single-unit transfusion policy with } \\
\text { administration of one unit at a time } \\
\text { titrated to symptom resolution }\end{array}$ & $\begin{array}{l}\text { - Rapid hemoglobin improvement } \\
\text { - Rapid improvement in anemia } \\
\text { symptoms } \\
\text { - Improve quality of life }\end{array}$ & $\begin{array}{l}\text { - Pathogen transmission } \\
\text { - Transfusion reaction } \\
\text { - Alloimmunization } \\
\text { - Increased thrombotic risk } \\
\text { - TACO } \\
\text { - May impact disease progression } \\
\text { - Iron overload }\end{array}$ \\
\hline ESA administration & $\begin{array}{l}\text { - Symptomatic ClA } \\
\text { - Consider when } \mathrm{Hb} \leq 10 \mathrm{~g} / \mathrm{dL}\end{array}$ & $\begin{array}{l}\text { - Reduce RBC requirements } \\
\text { - Diminished severity and } \\
\text { duration of CIA } \\
\text { - Improve quality of life }\end{array}$ & $\begin{array}{l}\text { - Increased thrombotic risk } \\
\text { - Hyperviscosity-associated } \\
\text { complications } \\
\text { - Hypertension } \\
\text { - Seizures } \\
\text { - Pure red cell aplasia } \\
\text { - Slow to improve hemoglobin }\end{array}$ \\
\hline $\begin{array}{l}\text { Intravenous iron } \\
\text { supplementation }\end{array}$ & $\begin{array}{l}\text { - Absolute iron deficiency } \\
\text { (TSAT }<20 \% \text {, ferritin }<30 \mathrm{ng} / \mathrm{mL})^{7} \\
\text { - Functional iron deficiency } \\
(\text { TSAT }<50 \% \text {, ferritin } 30-500 \mathrm{ng} / \\
\mathrm{mL})^{7} \\
\text { - Consider when } \mathrm{Hb} \leq \mathrm{I} \text { I or has } \\
\text { decreased by } \geq 2 \mathrm{~g} / \mathrm{dL} \text { from } \\
\text { baseline level } \geq 12 \mathrm{~g} / \mathrm{dL} \text { in the } \\
\text { setting of absolute iron deficiency } \\
\text { as defined by serum ferritin }<100 \\
\mathrm{ng} / \mathrm{mL}^{29} \\
\text { - Consider prior to ESA } \\
\text { administration }\end{array}$ & $\begin{array}{l}\text { - Reduces RBC requirements } \\
\text { - Facilitates optimal ESA response }\end{array}$ & $\begin{array}{l}\text { - Iron overload } \\
\text { - Hypertension } \\
\text { - Nausea, vomiting, diarrhea } \\
\text { - Headache } \\
\text { - Dizziness } \\
\text { - Dyspnea } \\
\text { - Pruritus } \\
\text { - Slow to improve hemoglobin }\end{array}$ \\
\hline
\end{tabular}

Abbreviations: CIA, chemotherapy-induced anemia; TACO, transfusion associated circulatory overload; Hb, hemoglobin; ESA, erythropoietin stimulating agent; RBC, red blood cell; TSAT, transferrin saturation.

\section{Future directions in treatment of CIA and anticipated reduction of red blood cell transfusions}

The development of screening assays utilizing hematopoietic stem and progenitor cells (HPCs CD34+) from peripheral blood and bone marrow help to evaluate the effects of chemotherapy-induced myelosuppression and may identify particularly cytotoxic pharmacologic therapies. ${ }^{106}$ In addition to novel screening mechanisms, various hormones and pharmacologic agents influence the prevention and management of CIA. Administration of FLT3 tyrosine kinase inhibitors following chemotherapy may selectively induce myelosuppression of neoplastic cells, but not bone marrow progenitor cells. ${ }^{12}$ Arginine vasopressin, eryptosis inhibitors, transforming growth factor beta inhibitors, and drugs that disrupt the HIF-1 $\alpha$ pathway may help to preserve and stimulate erythropoiesis as well as to protect renal tubular and endothelial cells..$^{39,107-109}$ Roxadustat, a reversible HIF prolyl hydroxylase inhibitor, increases expression of both erythropoietin as well as erythropoietin receptors and is under investigation to reduce red blood cell transfusion requirements. ${ }^{110}$ Prevention, early recognition, and prompt treatment of CIA will optimistically translate to fewer dose delays, fewer dose reductions, and improved patient outcomes.

\section{Disclosure}

The authors report no conflicts of interest in this work.

\section{References}

1. Radziwon P, Krzakowski M, Kalinka-Warzocha E. Anemia in cancer patients-expert group recommendations. Oncol Clin Pract. 2017;13(5):202-210.

2. van Belle SJ, Cocquyt V. Impact of haemoglobin levels on the outcome of cancers treated with chemotherapy. Crit Rev Oncol Hematol. 2003;47(1):1-11.

3. Gilreath JA, Stenehjem DD, Rodgers GM. Diagnosis and treatment of cancer-related anemia. Am J Hematol. 2014;89(2):203-212.

4. Langer CJ, Choy H, Glaspy JA, Colowick A. Standards of care for anemia management in oncology. Cancer. 2002;95(3):613-623.

5. Kirshner J, Hatch M, Hennessy DD, Fridman M, Tannous RE. Anemia in stage II and III breast cancer patients treated with adjuvant doxorubicin and cyclophosphamide chemotherapy. Oncologist. 2004;9(1):25-32.

6. Groopman JE, Itri LM. Chemotherapy-induced anemia in adults: incidence and treatment. J Natl Cancer Inst. 1999;91(19):1616-1634.

7. NCCN Clinical Practice Guidelines in Oncology. Cancer and Chemotherapy Induced Anemia. National Comprehensive Cancer Network. Version 2, 2018. Available from: https://www.nccn.org. Accessed November 11, 2018. 
8. Barrett-Lee PJ, Ludwig H, Birgegård G, et al. Independent risk factors for anemia in cancer patients receiving chemotherapy: results from the European Cancer Anaemia Survey. Oncology. 2006;70(1):34-48.

9. Ludwig H. Iron metabolism and iron supplementation in anemia of cancer. Semin Hematol. 2006;43:S13-S17.

10. Henry D. Haematological toxicities associated with dose-intensive chemotherapy, the role for and use of recombinant growth factors. Ann Oncol. 1997;8(Suppl 3):S7-S10.

11. Adamson JW. The anemia of inflammation/malignancy: mechanisms and management. Hematology. 2008;2008(1):159-165.

12. Taylor SJ, Duyvestyn JM, Dagger SA, et al. Preventing chemotherapyinduced myelosuppression by repurposing the FLT3 inhibitor quizartinib. Sci Transl Med. 2017;9(402):eaam8060.

13. Lang E, Lang F. Triggers, inhibitors, mechanisms, and significance of eryptosis: the suicidal erythrocyte death. Biomed Res Int. 2015;2015(2):1-16.

14. Lichtiger B, Huh YO. Transfusion therapy for patients with cancer. $C A$ Cancer J Clin. 1985;35(5):311-316.

15. Bohlius J, Schmidlin K, Brillant C, et al. Erythropoietin or Darbepoetin for patients with cancer - meta-analysis based on individual patient data. Cochrane Database Syst Rev. 2009(3):CD007303.

16. Clarke H, Pallister CJ. The impact of anaemia on outcome in cancer Clin Lab Haematol. 2005;27(1):1-13.

17. Tas F, Eralp Y, Basaran M, et al. Anemia in Oncology Practice. Am J Clin Oncol. 2002;25(4):371-379.

18. Skillings JR, Sridhar FG, Wong C, Paddock L. The frequency of red cell transfusion for anemia in patients receiving chemotherapy. A retrospective cohort study. Am J Clin Oncol. 1993;16(1):22-25.

19. Barrett-Lee PJ, Bailey NP, O’Brien ME, Wager E. Large-scale UK audit of blood transfusion requirements and anaemia in patients receiving cytotoxic chemotherapy. Br J Cancer. 2000;82(1):93-97.

20. Bamias A, Aravantinos G, Kalofonos C, et al. Prevention of anemia in patients with solid tumors receiving platinum-based chemotherapy by recombinant human Erythropoietin ( $\mathrm{rHuEpo}$ ): a prospective, open label, randomized trial by the Hellenic Cooperative Oncology Group. Oncology. 2003;64(2):102-110.

21. Pivot X, Guardiola E, Etienne M, et al. An analysis of potential factors allowing an individual prediction of cisplatin-induced anaemia. Eur J Cancer. 2000;36(7):852-857.

22. Spivak JL, Gascón P, Ludwig H. Anemia management in oncology and hematology. Oncologist. 2009;14(Suppl 1):43-56.

23. Rothmann SA, Paul P, Weick JK, Mcintyre WR, Fantelli F. Effect of cis-diamminedichloroplatinum on erythropoietin production and hematopoietic progenitor cells. Int J Cell Cloning. 1985;3(6) 415-423.

24. Wood PA, Hrushesky WJ. Cisplatin-associated anemia: an erythropoietin deficiency syndrome. J Clin Invest. 1995;95(4):1650-1659.

25. Groopman JE, Itri LM. Chemotherapy-induced anemia in adults: incidence and treatment. J Natl Cancer Inst. 1999;91(19):1616-1634

26. Reitan JF, Kudrik FJ, Fox K, van Breda A, Shreay S, Corey-Lisle PK. The burden of blood transfusion: a utilization and economic analysis - a pilot study in patients with chemotherapy-induced anemia (CIA). J Med Econ. 2013;16(5):633-638.

27. Wright JR, Ung YC, Julian JA, et al. Randomized, double-blind, placebo-controlled trial of erythropoietin in non-small-cell lung cancer with disease-related anemia. J Clin Oncol. 2007;25(9):1027-1032.

28. Ludwig H, Fritz E. Anemia in cancer patients. Semin Oncol. 1998; 3(Suppl 7):2-6.

29. Aapro M, Beguin Y, Bokemeyer C, et al. Management of anaemia and iron deficiency in patients with cancer: ESMO Clinical Practice Guidelines. Ann Oncol. 2018;29(Suppl 4):iv96-iv110.

30. Vadhan-Raj S, Mirtsching B, Charu V, et al. Assessment of hematologic effects and fatigue in cancer patients with chemotherapy-induced anemia given darbepoetin alfa every two weeks. J Support Oncol. 2003;1(2):131-138.

31. Bottini A, Berruti A, Brizzi MP, et al. Pretreatment haemoglobin levels significantly predict the tumour response to primary chemotherapy in human breast cancer. Br J Cancer. 2003;89(6):977-982.
32. Lyman GH, Lyman CH, Agboola O. Risk models for predicting chemotherapy-induced neutropenia. Oncologist. 2005;10(6):427-437.

33. Lyman GH. Chemotherapy dose intensity and quality cancer care Oncology. 2006;20(14 Suppl 9):16-25.

34. Family L, Xu L, Xu H, et al. The effect of chemotherapy-induced anemia on dose reduction and dose delay. Support Care Cancer. 2016;24(10):4263-4271.

35. Tarnawski R, Skladowski K, Maciejewski B. Prognostic value of hemoglobin concentration in radiotherapy for cancer of supraglottic larynx. Int J Radiat Oncol Biol Phys. 1997;38(5):1007-1011.

36. Stadler P, Becker A, Feldmann HJ, Putnik K, Kreimeyer T, et al. Influence of the hypoxic subvolume on the survival of patients with head and neck cancer. Int J Radiat Oncol Biol Phys. 1999;44(4):749-754.

37. Becker A, Stadler P, Lavey RS, et al. Severe anemia is associated with poor tumor oxygenation in head and neck squamous cell carcinomas. Int J Radiat Oncol Biol Phys. 2000;46(2):459-466.

38. Vaupel P. Hypoxia and aggressive tumor phenotype: implications for therapy and prognosis. Oncologist. 2008;13(Suppl 3):21-26.

39. Masoud GN, Li W. HIF-1 $\alpha$ pathway: role, regulation and intervention for cancer therapy. Acta Pharm Sin B. 2015;5(5):378-389.

40. Caro JJ, Salas M, Ward A, Goss G. Anemia as an independent prognostic factor for survival in patients with cancer: a systemic, quantitative review. Cancer. 2001;91(12):2214-2221.

41. Muz B, de La Puente P, Azab F, Azab AK, Kareem Azab A. The role of hypoxia in cancer progression, angiogenesis, metastasis, and resistance to therapy. Hypoxia. 2015;3:83-92.

42. Varlotto J, Stevenson MA. Anemia, tumor hypoxemia, and the cancer patient. Int J Radiat Oncol Biol Phys. 2005;63(1):25-36.

43. Topkan E, Selek U, Ozdemir Y, et al. Chemoradiotherapy-induced hemoglobin nadir values and survival in patients with stage III nonsmall cell lung cancer. Lung Cancer. 2018;121:30-36.

44. Ludwig H, Aapro M, Bokemeyer C, et al. A European patient record study on diagnosis and treatment of chemotherapy-induced anaemia. Support Care Cancer. 2014;22(8):2197-2206.

45. Koeller JM. Clinical guidelines for the treatment of cancer-related anemia. Pharmacotherapy. 1998;18(1):156-169.

46. Ye X, Liu J, Chen Y, Wang N, Lu R. The impact of hemoglobin level and transfusion on the outcomes of chemotherapy in gastric cancer patients. Int J Clin Exp Med. 2015;8(3):4228-4235.

47. Kassner E. Blood transfusion therapy. Pediatr Oncol Nurs. 2000;22: 413-424.

48. Whitaker B. The 2011 National Blood Collection and Utilization Survey Report. US Department of Health and Human Services; 2011. Available from: http://www.aabb.org/research/hemovigilance/bloodsurvey/ Documents/11-nbcus-report.pdf. Accessed November 11, 2018.

49. Crémieux PY, Barrett B, Anderson K, Slavin MB. Cost of outpatient blood transfusion in cancer patients. J Clin Oncol. 2000;18(14):2755-2761.

50. Hicks LK, Bering H, Carson KR, et al. The ASH Choosing Wisely® campaign: five hematologic tests and treatments to question. Blood. 2013;122(24):3879-3883.

51. Berger MD, Gerber B, Arn K, Senn O, Schanz U, Stussi G. Significant reduction of red blood cell transfusion requirements by changing from a double-unit to a single-unit transfusion policy in patients receiving intensive chemotherapy or stem cell transplantation. Haematologica. 2012;97(1):116-122. Accessed September 14, 2018.

52. American Association of Blood Banks. Standards for blood banks and transfusion services. 29th ed. 2014. Available from: http://www.aabb org/press/Pages/pr161012.aspx. Accessed November 11, 2018.

53. Nelson AH, Fleisher LA, Rosenbaum SH. Relationship between postoperative anemia and cardiac morbidity in high-risk vascular patients in the intensive care unit. Crit Care Med. 1993;21(6):860-866.

54. Whitman CB, Shreay S, Gitlin M, van Oijen MG, Spiegel BM. Clinical factors and the decision to transfuse chronic dialysis patients. Clin J Am Soc Nephrol. 2013;8(11):1942-1951.

55. Watkins T, Surowiecka MK, Mccullough J. Transfusion indications for patients with cancer. Cancer Control. 2015;22(1):38-46.

56. McCullough JJ. Complications in transfusion. In: Transfusion Medicine. 3rd ed. Chichester, WestSussex, UK: Wiley-Blackwell; 2011. 
57. Eder AF, Chambers LA. Noninfectious complications of blood transfusion. Arch Pathol Lab Med. 2007;131(5):708-718.

58. Schrijvers D. Management of anemia in cancer patients: transfusions. Oncologist. 2011;16(Suppl 3):12-18.

59. Hess JR, Storage Rcell. Red cell storage. J Proteomics. 2010;73(3): 368-373.

60. Benson DD, Beck AW, Burdine MS, Brekken R, Silliman CC, Barnett CC. Accumulation of pro-cancer cytokines in the plasma fraction of stored packed red cells. J Gastrointest Surg. 2012;16(3):460-468.

61. Blajchman MA. Transfusion immunomodulation or TRIM: what does it mean clinically? Hematology. 2005;10(Suppl 1):208-214.

62. Vamvakas EC, Blajchman MA. Deleterious clinical effects of transfusion-associated immunomodulation: fact or fiction? Blood. 2001;97(5):1180-1195.

63. Welsh L, Panek R, Riddell A, et al. Blood transfusion during radical chemo-radiotherapy does not reduce tumour hypoxia in squamous cell cancer of the head and neck. Br J Cancer. 2017;116(1):28-35.

64. Castillo JJ, Dalia S, Pascual SK. Association between red blood cell transfusions and development of non-Hodgkin lymphoma: a metaanalysis of observational studies. Blood. 2010;116(16):2897-2907.

65. Goubran HA, Elemary M, Radosevich M, Seghatchian J, El-Ekiaby $\mathrm{M}$, Burnouf T. Impact of transfusion on cancer growth and outcome. Cancer Growth Metastasis. 2016;9:1-8.

66. Khorana AA, Francis CW, Blumberg N, Culakova E, Refaai MA, Lyman GH. Blood transfusions, thrombosis, and mortality in hospitalized patients with cancer. Arch Intern Med. 2008;168(21):2377-2381.

67. Henry DH, Dahl NV, Auerbach MA. Thrombocytosis and venous thromboembolism in cancer patients with chemotherapy induced anemia may be related to ESA induced iron restricted erythropoiesis and reversed by administration of IV iron. Am J Hematol. 2012;87(3):308-310.

68. Kumar J, Reccia I, Kusano T, Agrawal S. A systematic review on the erythropoietin receptors expression in various cancers and importance of recombinant erythropoietin in chemotherapy induced anaemia. Hematol Transfus Int J. 2017;4(1):00072.

69. Weigl A, Köhler N, Monsef I, et al. Intravenous iron versus oral iron versus no iron with or without erythropoiesis- stimulating agents (ESA) for cancer patients with anaemia: a systematic review and network meta-analysis. Cochrane Database Syst Rev. 2017;26(10):1-20.

70. Forbes CA, Worthy G, Harker J, et al. Dose efficiency of erythropoiesis-stimulating agents for the treatment of patients with chemotherapy-induced anemia: a systematic review. Clin Ther. 2014;36(4): 594-610.

71. Henry DH, Brooks BJ, Case DC, et al. Recombinant human erythropoietin therapy for anemic cancer patients receiving cisplatin chemotherapy. Cancer J Sci Am. 1995;1(4):252-260.

72. Vansteenkiste J, Glaspy J, Henry D, et al. Benefits and risks of using erythropoiesis-stimulating agents (ESAs) in lung cancer patients: study-level and patient-level meta-analyses. Lung Cancer. 2012;76(3):478-485.

73. Thorp ML, Johnson ES, Yang X, Petrik AF, Platt R, Smith DH. Effect of anaemia on mortality, cardiovascular hospitalizations and end-stage renal disease among patients with chronic kidney disease. Nephrology. 2009;14(2):240-246.

74. Volberding PA, Levine AM, Dieterich D, et al. Anemia in HIV infection: clinical impact and evidence-based management strategies. Clin Infect Dis. 2004;38(10):1454-1463.

75. Demetri GD, Kris M, Wade J, Degos L, Cella D. Quality-of-life benefit in chemotherapy patients treated with epoetin alfa is independent of disease response or tumor type: results from a prospective community oncology study. Procrit Study Group. J Clin Oncol. 1998;16(10):3412-3425.

76. Glaspy J, Bukowski R, Steinberg D, Taylor C, Tchekmedyian S, Vadhan-Raj S. Impact of therapy with epoetin alfa on clinical outcomes in patients with nonmyeloid malignancies during cancer chemotherapy in community oncology practice. Procrit Study Group. J Clin Oncol. 1997;15(3):1218-1234.
77. Gabrilove JL, Cleeland CS, Livingston RB, Sarokhan B, Winer E, Einhorn LH. Clinical evaluation of once-weekly dosing of epoetin alfa in chemotherapy patients: improvements in hemoglobin and quality of life are similar to three-times-weekly dosing. J Clin Oncol. 2001;19(11):2875-2882.

78. Leyland-Jones B, BEST Investigators and Study Group. Breast cancer trial with erythropoietin terminated unexpectedly. Lancet Oncol. 2003;4(8):459-460.

79. FDA. Epogen (epoetin alfa) guidelines: full prescribers information. Thousand Oaks, CA: Amgen Inc. Available from: https://pi.amgen. $\mathrm{com} / \sim /$ media/amgen/repositorysites/pi-amgen-com/epogen/epogen_pi_hcp_english.pdf. Accessed November 11, 2018.

80. Glaspy J, Crawford J, Vansteenkiste J, et al. Erythropoiesis-stimulating agents in oncology: a study-level meta-analysis of survival and other safety outcomes. Br J Cancer. 2010;102(2):301-315.

81. Untch M, Fasching PA, Konecny GE, et al. PREPARE trial: a randomized phase III trial comparing preoperative, dose-dense, doseintensified chemotherapy with epirubicin, paclitaxel and CMF versus a standard-dosed epirubicin/cyclophosphamide followed by paclitaxel \pm darbepoetin alfa in primary breast cancer-results at the time of surgery. Ann Oncol. 2011;22(9):1988-1998.

82. Pirker R, Ramlau RA, Schuette W, et al. Safety and efficacy of darbepoetin alpha in previously untreated extensive-stage small-cell lung cancer treated with platinum plus etoposide. J Clin Oncol. 2008;26(14):2342-2349.

83. Bohlius J, Wilson J, Seidenfeld J, et al. Recombinant human erythropoietins and cancer patients: updated meta-analysis of 57 studies including 9353 patients. J Natl Cancer Inst. 2006;98(10):708-714.

84. del Mastro L, Venturini M, Lionetto R. Erythropoietin in the prevention of chemotherapy-induced anemia. JClin Oncol. 1997;15(7):2715-2721.

85 . Henry DH. The evolving role of epoetin alfa in cancer therapy. Oncologist. 2004;9(1):97-107.

86. $\mathrm{Xu} \mathrm{H}, \mathrm{Xu} \mathrm{L}$, Page JH, et al. Incidence of anemia in patients diagnosed with solid tumors receiving chemotherapy, 2010-2013. Clin Epidemiol. 2016;8:61-71.

87. Bennett CL, Silver SM, Djulbegovic B, et al. Venous thromboembolism and mortality associated with recombinant erythropoietin and darbepoetin administration for the treatment of cancer-associated anemia. JAMA. 2008;299(8):914-924.

88. Tonelli M, Hemmelgarn B, Reiman T, et al. Benefits and harms of erythropoiesis-stimulating agents for anemia related to cancer: a meta-analysis. CMAJ. 2009;180(11):E62-E71.

89. Ludwig H, Crawford J, Österborg A, et al. Pooled analysis of individual patient-level data from all randomized, double-blind, placebocontrolled trials of darbepoetin alfa in the treatment of patients with chemotherapy-induced anemia. J Clin Oncol. 2009;27(17):2838-2847.

90. Tonia T, Mettler A, Robert N. Erythropoietin or darbepoetin for patients with cancer. The Cochrane Library. 2012;12:288-675.

91. Crosby WH. The rationale for treating iron deficiency anemia. Arch Intern Med. 1984;144(3):471-472.

92. Weiss G, Goodnough LT. Anemia of chronic disease. $N$ Engl J Med Overseas Ed. 2005;352(10):1011-1023.

93. Naoum FA. Iron deficiency in cancer patients. Rev Bras Hematol Hemoter. 2016;38(4):325-330.

94. Rodgers GM, Becker PS, Blinder M, et al. Cancer- and chemotherapyinduced anemia. J Natl Compr Canc Netw. 2012;10(5):628-653.

95. Steensma DP, Sloan JA, Dakhil SR, et al. Phase III, randomized study of the effects of parenteral iron, oral iron, or no iron supplementation on the erythropoietic response to darbepoetin alfa for patients with chemotherapy-associated anemia. J Clin Oncol. 2011;29(1):97-105.

96. Henry DH, Dahl NV, Auerbach M, Tchekmedyian S, Laufman LR. Intravenous ferric gluconate significantly improves response to epoetin alfa versus oral iron or no iron in anemic patients with cancer receiving chemotherapy. Oncologist. 2007;12(2):231-242.

97. Hong J, Woo HS, Kim H, et al. Anemia as a useful biomarker in patients with diffuse large B-cell lymphoma treated with R-CHOP immunochemotherapy. Cancer Sci. 2014;105(12):1569-1575. 
98. Aapro M, Österborg A, Gascón P, Ludwig H, Beguin Y. Prevalence and management of cancer-related anaemia, iron deficiency and the specific role of i.v. iron. Ann Oncol. 2012;23(8):1954-1962.

99. Brugnara C, Chambers LA, Malynn E, Goldberg MA, Kruskall MS. Red blood cell regeneration induced by subcutaneous recombinant erythropoietin: iron-deficient erythropoiesis in iron-replete subjects. Blood. 1995;81(4):956-964.

100. Goodnough LT, Nemeth E, Ganz T. Detection, evaluation, and management of iron-restricted erythropoiesis. Blood. 2010;116(23):4754-4761.

101. Ludwig H, Evstatiev R, Kornek G, et al. Iron metabolism and iron supplementation in cancer patients. Wien Klin Wochenschr. 2015;127(23-24):907-919.

102. Finch CA, Huebers H. Perspectives in iron metabolism. NEngl J Med. 1982;306(25):1520-1528.

103. Uhm J. Patient blood management: an internist's perspective. Hanyang Med Rev. 2018;38(1):38-48.

104. Littlewood TJ, Bajetta E, Nortier JW, Vercammen E, Rapoport B; Epoetin Alfa Study Group. Effects of epoetin alfa on hematologic parameters and quality of life in cancer patients receiving nonplatinum chemotherapy: results of a randomized, double-blind, placebocontrolled trial. J Clin Oncol. 2001;19(11):2865-2874.
105. Auerbach M. Intravenous iron in chemotherapy-induced anemia. Am J Hematol. 2014;89(12):1153.

106. Javarappa KK, Tsallos D, Heckman CA. A Multiplexed screening assay to evaluate chemotherapy-induced myelosuppression using healthy peripheral blood and bone marrow. SLAS Discov. 2018;23(7): 687-696.

107. Miller RL, Sandoval PC, Pisitkun T, Knepper MA, Hoffert JD. Vasopressin inhibits apoptosis in renal collecting duct cells. Am J Physiol Renal Physiol. 2013;304(2):F177-F188.

108. Al Mamun Bhuyan A, Bissinger R, Cao H, Lang F. Inhibition of erythrocyte cell membrane scrambling by ASP3026. Cell Physiol Biochem. 2017;43(2):507-517.

109. Carrancio S, Markovics J, Wong P, et al. An activin receptor IIA ligand trap promotes erythropoiesis resulting in a rapid induction of red blood cells and haemoglobin. Br J Haematol. 2014;165(6):870-882.

110. Leong R. Phase 3 Randomized Double-Blind Placebo-Controlled Study Investigating the Efficacy and Safety of Roxadustat for Treatment of Anemia in Patients with Lower Risk Myelodysplastic Syndrome and Low Red Blood Cell Transfusion Burden. Ongoing Clinical Study. San Francisco, CA: Fibrogen; Approved 2017.
International Journal of Clinical Transfusion Medicine

\section{Publish your work in this journal}

International Journal of Clinical Transfusion Medicine is an international, peer-reviewed, open access, online journal publishing clinicalexperimental, policy-making and evidence-based practices of all topics pertaining to clinical transfusion medicine. Original research, short reports, reviews, case reports and commentaries are invited

\section{Dovepress}

The manuscript management system is completely online and includes a very quick and fair peer-review system, which is all easy to use. Visit http://www.dovepress.com/testimonials.php to read real quotes from published authors.

Submit your manuscript here: https://www.dovepress.com/international-journal-of-clinical-transfusion-medicine-journal 